\title{
Involvement of Patients in Health Technology Assessment: Further Perspectives for Informing Decision-Makers
}

\author{
David Hailey $^{1 *}$ \\ ${ }^{1}$ Department of Computing and Information Technology, University of Wollongong, Wollongong, Australia \\ *Corresponding Author: David Hailey, Ph.D., Professor, Department of Computing and Information Technology, \\ University of Wollongong, Wollongong, Australia. Tel: +61-262316539, Email: dhailey@ozemail.com.au
}

Received May 26, 2017; Accepted August 13, 2017; Online Published August 26, 2017

\begin{abstract}
Health technology assessment (HTA) is an evaluative process used to inform technology-related policymaking in healthcare. Interest in involving patients in the HTA process is increasing. Patients can provide additional perspectives to those of other groups that are concerned with health technology. Information on patients' perspectives is preferably obtained through reviews of published studies. Primary research approaches can be used if good quality, published evidence is unavailable. There are good examples of input from patients influencing the scope or preparation of HTA reports and subsequent consideration of these reports by decision-makers. One challenge to achieving effective patient involvement is finding suitable resources for patient organizations and HTA agencies. There is also a need for the further development of methods, for example, for use in rapid evidence reviews. HTA programs and the decision-makers they inform have to make choices about when patient input is appropriate. Such choices will include considering which questions or aspects of a technology requires such input and the expected time lines for assessment.

Keywords: Health Technology Assessment, Patient Involvement, Decision-Making, Outcomes, Challenges
\end{abstract}

\section{Background}

Health technology assessment (HTA) is the systematic evaluation of properties, effects, and/or impacts of healthcare technology (including drugs, devices, procedures, and information systems). Its main purpose is to inform technology-related policymaking in healthcare, often relating to decisions on whether or how the use of health technologies should be supported. In undertaking HTA, the focus is often on organizations and individuals that have major financial or operational responsibilities for health technologies, including government agencies, the healthcare sector, health insurance, and manufacturing industries. Less attention has been given to involving patients and their caregivers in the HTA process. ${ }^{1}$

The International Network of Agencies for Health Technology Assessment (INAHTA) is a group of organizations from 34 countries that provide advice to government decision-makers. In 2005, a survey by INAHTA found that most of its member agencies involved patients in some aspects of their programs, although not always routinely. ${ }^{2}$ Agencies propounded that the involvement of patients offered the potential to broaden the perspective of assessments and of the advice provided to decision-makers. Perceived difficulties included issues with time constraints when projects were carried out in response to urgent requests and the need for resources for the identification and training of suitable patient representatives (both organizations and individuals). ${ }^{3}$

These findings provided input to the establishment by Health Technology Assessment international (HTAi) for formation of an Interest Group for Patient/Citizen Involvement. The Interest Group has developed as a forum for promoting the incorporation of patients' perspectives into HTAs and engaging them in the HTA process. ${ }^{4} \mathrm{~A}$ follow-up survey of INAHTA agencies suggested that the level of patient involvement remained relatively restricted with limited inclusion of patient perspectives in assessment reports. ${ }^{5}$

\section{Objective}

The current study purposed to present an overview of the current status of patient involvement in HTA and to consider issues facing HTA agencies in their provision of information to policy, administrative, and clinical decision-makers.

Copyright $\odot 2017$ The Author(s). This is an open-access article distributed under the terms of the Creative Commons Attribution License (http:// creativecommons.org/licenses/by/4.0), which permits unrestricted use, distribution, and reproduction in any medium, provided the original work is properly cited. 


\section{Methods}

A narrative review was undertaken, drawing on current sources of authoritative information on issues related to the involvement of patients in HTA. Inclusion criteria for publications were that they appropriately covered (a) studies and experience with approaches to incorporating patient preferences into HTA reports and the decisionmaking processes that they inform; $(b)$ involvement of patients in decision-making related to HTA findings; and $(c)$ the effects of patient involvement in HTA on administrative and clinical outcomes.

Relevant material was obtained from a recent guide on this topic which included many chapters prepared by members of the HTAi Interest Group ${ }^{6}$ and from the websites of INAHTA (http://www.inahta.org) and HTAi (http://www.htai.org/interest-groups/patient-and-citizeninvolvement.html).

As a check for recent publications, a search of PubMed from 2014 to June 2017 was undertaken using the keywords health technology assessment, patient participation, and decision-making. Credible details were extracted from studies and reviews that referred to conceptual issues, research methodologies, and the interaction of HTA agencies with patients and decision-makers.

\section{Results}

\subsection{Reasons for Involving Patients in HTA}

The HTAi Interest Group pointed out that HTA was still driven by the assessment of quantitative evidence from controlled studies and economic modelling to describe the clinical and cost effectiveness of a health technology. Broader social and psychological aspects related to the use of a health technology were often only considered implicitly by those who developed and used HTA. Few HTA agencies had used robust methods to gather evidence about the social and psychological aspects of living with an illness or using a technology. ${ }^{4}$ Patients are a key source for such evidence.

Patients have unique knowledge that can be useful to HTA. The experience of living with a condition or using healthcare services can provide an additional view to that of experts. This offers a real world understanding of an illness and the benefits and disadvantages of using particular technologies in its management.

Involving patients is also a means of improving transparency and openness in public policy. "Being open to more effective patient participation in the HTA process may be important to improve the social legitimacy and implementation of HTA recommendations." 4 Facey suggested that patient involvement in HTA may help with the difficult value judgements that arise when clinical and economic evidence is limited, or if added value is at the cusp of a pre-defined threshold, by explaining the realworld implications for patients. ${ }^{7}$

\subsection{Obtaining Evidence on Patients' Perspectives}

Use of published evidence is the preferred initial approach to obtaining evidence on patients' perspectives. The HTAi Interest Group indicated that the first phase of gathering evidence on patients' perspectives for an HTA is to conduct a systematic review of existing secondary and primary studies. This will identify research questions of relevance to a particular assessment and perspectives about issues that have already been identified in scoping. ${ }^{4}$ If evidence of a reasonable quality is not available for the technology that is being assessed, is not transferable to the context considered in the HTA, or is of low quality, the generation of primary research data is appropriate as an alternative source of information.

Methods for generating evidence to determine patients' perspectives include qualitative research and individual and focus group interviews. Observation of individuals in a real-life setting (field work) can complement the subjective information reported by participants. Quantitative data on patients' perspectives can be generated from survey questionnaires. Relevant information may also be available from patient organizations.

Other approaches that have been considered include patient-reported outcome measures, discrete choice experiments, ethnographic fieldwork, deliberative democracy, and use of social media to elicit patients' perspectives. These methods provide options for broadening assessment approaches and patient involvement. However, some of them are time-consuming and expensive and may require expertise that is not easily available to HTA programs. ${ }^{6}$

Multi-criteria decision analysis (MCDA) offers a possible approach for eliciting details of preferences and trade-offs in relation to alternate health technologies for informing decision criteria. ${ }^{8}$

\subsection{Patient Input to HTA}

Patient input to HTA refers to the information that patient groups and individual patients submit to organizations undertaking HTA as distinguished from patient evidence derived from the literature or primary studies. ${ }^{9}$ Patients may provide comment on the scope and approach of an assessment or on contextual knowledge that is not available in scientific evidence. ${ }^{9}$ In this way, patients have some involvement in the HTA process and contribute to the requirement for HTA programs to communicate effectively with the decision-makers whom they inform. ${ }^{1}$

To provide such input, patients and their caregivers must interact in some way with organizations that are responsible for undertaking HTAs. The composition and operation of these organizations vary considerably between countries and regions. The organizational structures and political context of HTA programs and decision-makers can be complex. They tend to change over time, reflecting political and governance decisions that can have consequences for patient involvement. ${ }^{6}$ In Germany and Taiwan, patient involvement in HTA is specified in legislation, ${ }^{10,11}$ and it has been a strong policy focus of the Scottish Parliament. ${ }^{12}$ Approaches open to patients for informing HTA 
include providing written comments on draft documents, submitting written information, and face-to-face participation in committees. ${ }^{9}$ Many HTA programs offer opportunities for patient organizations to provide input. ${ }^{6}$ Some programs also allow individuals to provide comments to committees or multi-stakeholder advisory groups. There is increasing inclusion of patient representatives on committees, typically through nomination by patient organizations. In some HTA programs, submissions may be considered without feedback to the patient organization or individual, so that there is no interactive component in the process.

\subsection{Challenges for Patient Involvement}

Difficulties for HTA programs with patient involvement can arise with organizing input from patient representatives, in finding resources, and in meeting timelines. The recruitment and training of patient representatives on committees and obtaining their input to discussion can be demanding. Suitable support must be provided if patient representatives are to contribute effectively. HTA programs have sought improvement in these areas by developing approaches to involve and encourage patient participation. ${ }^{6}$

Effective patient involvement in HTA depends on appropriate input to assessments from patient organizations. There will be limits to what can be done from their usual resources. Sources of funding may need to be identified to ensure that these organizations are a sustainable resource for HTA. It may be difficult for HTA programs to commit funding to patient involvement from limited budgets.

The extent of patient involvement is also determined by other factors, including the nature of interaction of patient representatives with other stakeholders and the approaches used to include their views in the formulation of an HTA. For example, Australian advisory committees have had difficulty in bringing together the diversity of their views with those of patient organizations. ${ }^{13}$ Social values related to justice and equity are considered, but without quantification weights for equity relative to other factors. ${ }^{14}$

\subsection{Outcomes of Patient Involvement}

The outcomes of patient involvement in HTA may be difficult to closely identify or quantify. Details on how patients have contributed to assessments are required to refine approaches taken by HTA programs, to provide input to reviews of those programs and their requests for funding, and for feedback to patient organizations.

There are cases where patient involvement has clearly had an important influence on the scope or organization of an HTA. The examples shown in Table 1 illustrate the range of topics that may be considered for assessment. Input from patients influenced the preparation of the assessment reports and subsequent consideration by decision-makers. ${ }^{15-19}$

In many cases, outcomes associated with patient involvement are less clear and can be difficult to pin down. The extent of patient and caregiver involvement can be documented by recording the receipt of communications from them, for example, through the use of patient input templates. ${ }^{6}$ However, it is challenging to track the impact of information collected through a patient input template on the assessment or on deliberations by decision-makers. ${ }^{12}$ Communication by the HTA program with patient organizations and other stakeholders can also be recorded. Beyond this basic level, however, there are issues regarding to what extent patient involvement has influenced the preparation of HTAs and the decisions that they inform.

\section{Discussion}

The experiences of the programs in several countries show that progress has been made in patient involvement in HTA since the surveys undertaken by the INAHTA. Much of this progress is attributable to the efforts of the HTA community and of patient organizations. There is growing acceptance within government organizations of the fact that patient involvement has a useful place in decision-making. There is also increased sensitivity at the political level to patients' rights and perspectives and to pressures imposed by social media. ${ }^{20}$ However, decisions made on health technologies and the extent of patient

Table 1. Examples of Patient Involvement in HTAs

\begin{tabular}{|c|c|c|c|}
\hline Country & Topic & Patient Involvement & Outcome \\
\hline Brazil $^{15}$ & Management of rare diseases & $\begin{array}{l}1140 \text { responses from organizations } \\
\text { and individuals }\end{array}$ & Modification of a clinical guideline \\
\hline Canada $^{16}$ & $\begin{array}{l}\text { Alternatives to restraint and seclusion of } \\
\text { adults in long-term care facilities }\end{array}$ & $\begin{array}{l}\text { Individual semi-structured interviews } \\
\text { with } 13 \text { stakeholders }\end{array}$ & $\begin{array}{l}\text { Input to development of a management } \\
\text { strategy }\end{array}$ \\
\hline Italy ${ }^{17}$ & Wireless capsule endoscopy & $\begin{array}{l}127 \text { responses to a questionnaire on } \\
\text { preferences and alternative treatments }\end{array}$ & $\begin{array}{l}\text { Incorporation of views into an HTA } \\
\text { report }\end{array}$ \\
\hline Scotland ${ }^{18}$ & Anti-microbial dressings for chronic wounds & Primary qualitative research & $\begin{array}{l}\text { Input to preparation of all sections of } \\
\text { an HTA report }\end{array}$ \\
\hline Sweden ${ }^{19}$ & $\begin{array}{l}\text { Patient participation in decision-making in } \\
\text { cases of psychosis/schizophrenia, ADHD, } \\
\text { and autism spectrum }\end{array}$ & $\begin{array}{l}\text { Obtaining patient evidence using } \\
\text { qualitative evidence synthesis }\end{array}$ & $\begin{array}{l}\text { Inclusion of patients' experiences in } \\
\text { HTA reports }\end{array}$ \\
\hline
\end{tabular}


involvement have varied between different health systems, reflecting differences in political and societal perspectives. As with other aspects of HTA, patient input will be one of several kinds of information used by decision-makers. ${ }^{1}$ Potentially, patient involvement could play a major role through the provision of information related to the safety and effectiveness of technologies and services that are in routine use within health systems. ${ }^{20}$

While there are many positive points about the current use of patient involvement in HTA, various challenges remain related to resources, organizational arrangements, and methodological demands. Better links are needed between patient input to HTA and for what and how such input is utilized. ${ }^{12}$ Further development of qualitative methods and methods for qualitative evidence synthesis seems necessary. Patient involvement can be challenging with rapid HTAs which put pressure both on patient organizations and HTA program staff. HTA programs have to further develop their ability to routinely record and report on the contribution of patient involvement activities to the preparation of assessments and of advice to decisionmakers. Pressures on the process can also develop from changes within ministries and in government policies.

HTA programs and the decision-makers they inform have to make choices on when patient input is appropriate. These choices will involve considering which questions or aspects of a technology requires such input. Flexible approaches will be needed for each HTA program and assessment topic, taking account of both timelines and available resources.

\section{Conclusion}

Use of patient involvement in HTA is increasing in many countries and offers additional perspectives for decisionmaking in support of healthcare. Challenges remain in organizational arrangements, levels of resources, and methodological approaches.

\section{Conflict of Interest Disclosures}

The author declare that they have no conflicts of interest.

\section{Ethical Approval}

Not applicable.

\section{References}

1. Hailey D, Babidge W, Cameron A, Davignon L-A. HTA agencies and decision makers. An INAHTA guidance document. Stockholm: INAHTA; 2010.

2. Hailey D, Nordwall M. Survey on the involvement of consumers in health technology assessment programs. Int J Technol Assess Health Care. 2006;22(4):497-499. doi:10.1017/ s0266462306051427.

3. Hailey D. Consumer involvement in Health Technology Assessment. Edmonton: Alberta Heritage Foundation for Medical Research, HTA Initiatives \#21; December 2005. http://www.ihe.ca/advanced-search/consumer-involvement-inhealth-technology-assessment.

4. Facey K, Boivin A, Gracia J, et al. Patients' perspectives in health technology assessment: a route to robust evidence and fair
Review Highlights

What Is Already Known?

- HTA, a process to inform health policymaking, has focused on the appraisal of quantitative clinical and economic studies.

- Appraisal of the social and psychological aspects of health technology use can offer additional perspectives for consideration by decision-makers.

- Involvement of patients by HTA agencies in their assessments has been limited.

\section{What This Study Adds?}

- Involvement of patients in HTA is increasing in many countries.

- Benefits to decision-making processes through such involvement have been demonstrated.

- Continuing challenges include the appropriate integration of patient perspectives with those from other stakeholders in HTA and the further development and application of methodological approaches.

deliberation. Int J Technol Assess Health Care. 2010;26(3):334340. doi:10.1017/s0266462310000395.

5. Hailey D, Werko S, Bakri R, et al. Involvement of consumers in health technology assessment activities by Inahta agencies. Int J Technol Assess Health Care. 2013;29(1):79-83. doi:10.1017/ s026646231200075x

6. Facey KM, Hansen HP, Single ANV, editors. Patient Involvement in HTA. Singapore: Springer; 2017. doi:10.1007/978-981-104068-9.

7. Facey K. Health technology assessment and patient involvement. In: Facey KM, Hansen HP, Single ANV, eds. Patient Involvement in HTA. Singapore: Springer; 2017. doi:10.1007/978-981-10-4068-9_1.

8. Muhlbacher AC, Juhnke C. [Involving patients, the insured and the general public in healthcare decision making]. Z Evid Fortbild Qual Gesundhwes. 2016;110-111:36-44. doi:10.1016/j.zefq.2015.12.001.

9. Facey K, Single A. Patient input to HTA. In: Facey KM, Hansen HP, Single ANV, eds. Patient Involvement in HTA. Singapore: Springer; 2017. doi:10.1007/978-981-10-4068-9_6.

10. Haefner S, Danner M. Patient involvement in German HTA and policy-making institutions: incorporating patients' individual and collective experiences. In: Facey KM, Hansen HP, Single ANV, eds. Patient Involvement in HTA. Singapore: Springer; 2017.

11. Tarn $\mathrm{Y}-\mathrm{H}$. Patient involvement in HTA process in Taiwan. In: Facey KM, Hansen HP, Single ANV, eds. Patient Involvement in HTA. Singapore: Springer; 2017.

12. Scottish Executive. Patient focus and public Involvement. 2001. http://www.gov.scot/Resource/Doc/158744/0043087.pdf.

13. Lopes E, Street J, Carter D, Merlin T. Involving patients in health technology funding decisions: stakeholder perspectives on processes used in Australia. Health Expect. 2016;19(2):331 344. doi:10.1111/hex.12356.

14. Whitty JA, Littlejohns P. Social values and health priority setting in Australia: an analysis applied to the context of health technology assessment. Health Policy. 2015;119(2):127-136. doi:10.1016/j.healthpol.2014.09.003.

15. Silva AS, Petramale CA, Rabelo RB, Santos VCC. Patient 
involvement in HTA in Brazil. In: Facey KM, Hansen HP, Single ANV, eds. Patient Involvement in HTA. Singapore: Springer; 2017.

16. Dipankui MT, Gagnon MP, Desmartis M, et al. Evaluation of patient involvement in a health technology assessment. Int J Technol Assess Health Care. 2015;31(3):166-170. doi:10.1017/ s0266462315000240.

17. Lo Scalzo A. Patients' involvement in HTA: the AGENAS case. In: Facey KM, Hansen HP, Single ANV, eds. Patient Involvement in HTA. Singapore: Springer; 2017.

18. Scottish Health Technologies Group. Antimicrobial wound dressings (AWDs) for chronic wounds. Health technology assessment report 13. 2015. http://www. healthcareimprovementscotland.org/our_work/technologies_and_ medicines/shtg_-_hta/hta13_antimicrobial_dressings.aspx

19. Werkö S, Andersson C. Patient involvement in Swedish HTA organisations. In: Facey KM, Hansen HP, Single ANV, eds. Patient Involvement in HTA. Singapore: Springer; 2017.

20. Hailey D. Discussion of approaches in different countries. In: Facey KM, Hansen HP, Single ANV, eds. Patient Involvement in HTA. Singapore: Springer; 2017. 